\title{
Laparoscopic pyeloplasty in ureteropelvic junction obstruction: A single-center experience
}

\author{
Mehmet Kutlu Demirkol,' @ Osman Barut, ${ }^{1} @$ Tayfun Şahinkanat, ${ }^{1} \odot$ Sefa Resim, ${ }^{1}$ \\ Ömer Faruk Boran² \\ 'Department of Urology, Kahramanmaras Sutcu Imam University, Faculty of Medicine, Kahramanmaras, Turkey \\ ${ }^{2}$ Department of Anesthesiology and Reanimation, Kahramanmaras Sutcu Imam University, Faculty of Medicine, Kahramanmaras, Turkey
}

\begin{abstract}
Introduction: The aim of the study is to retrospectively evaluate the perioperative and post-operative outcomes of the initial laparoscopic pyeloplasties (LPs); we performed in our clinic in the treatment of ureteropelvic junction obstruction (UPJO).

Materials and Methods: The data of 23 patients who underwent LP with the diagnosis of UPJO between February 2016 and March 2020 in our clinic were retrospectively analyzed. The charts of patients such as demographic data, presenting complaint, pre-operative imaging, operation time, presence of crossing aberrant vessel, post-operative complications, hemoglobin drop, length of drain and hospital stay, and success rates were evaluated.

Results: The mean age of patients was $25.5 \pm 17.1$ (4-63) years with a male predominance of $56.5 \%$. Of the 23 patients, 22 had primary and one patient had secondary UPJO previously treated with retrograde endopyelotomy. The mean operative time, drain stay time, and hospital stay time were $214.8 \pm 43.1(160-310)$ min, $2.8 \pm 1.0(2-7)$ days, and $3.5 \pm 1.8(2-9)$ days, respectively. Although no major operative or post-operative complications were seen in our series, $2(8.7 \%)$ patients had minor operative complications and $4(17.3 \%)$ patients had minor postoperative complications. The mean follow-up period of all patients followed for at least 3 months was $13.9 \pm 7.8(3-34)$ and the surgical success rate was $95.7 \%$.

Conclusion: Due to increased worldwide experience in laparoscopic surgery, the challenge on intracorporeal suturing of LP in initial cases is overcome in a short time. With a high success rate, low post-operative complication rate, and low hospital stay, our initial series results are consistent with high-volume studies in the literature.

Keywords: Laparoscopy; pyeloplasty; ureteropelvic junction obstruction.
\end{abstract}

\section{Introduction}

Ureteropelvic junction obstruction (UPJO) is a congenital or acquired disease characterized by restricted passage of urine from the renal pelvis to the ureter due to intrinsic or extrinsic causes. ${ }^{[1]}$ While intrinsic causes such as adynamic or atretic segments are more common, extrinsic causes such as fibrous bands or crossing aberrant vessels are also seen. Although UPJO shows a different incidence in pediatric and adult age, its overall incidence is 1 in $1.500 .{ }^{[2]}$ Uncorrected disease can cause increased intrarenal pressure, hydronephrosis involving the renal pelvis and calyces, loss of nephrons, and, consequently, 
renal failure. ${ }^{[3]}$ Therefore, in surgical indications such as significant pain or reduced kidney function, surgical correction of the UPJO is crucial to prevent further kidney damage..$^{[4]}$

Open pyeloplasty (OP) with the dismembered technique described by Anderson and Hynes is the traditional gold standard for surgical treatment of UPJO ${ }^{[5]}$ Search for minimally invasive techniques has led to endoscopic correction of the UPJO, such as antegrade or retrograde endopyelotomy, but it has little place in the treatment due to varying success rates and high recurrence rates. ${ }^{[6,7]}$ It was first described in 1993 by Schuessler et al., ${ }^{[8]}$ laparoscopic pyeloplasty (LP) was the first minimally invasive technique that achieved success rates of OP worldwide. ${ }^{[9]}$ In addition, LP has offered additional advantages such as low morbidity, short hospital stay, and short recovery period but it has challenges about intracorporeal suturing. ${ }^{[10]}$ Herein, we aimed to retrospectively evaluate the perioperative and post-operative outcomes of LP in our tertiary institution.

\section{Materials and Methods}

\section{Patients}

This observational retrospective study reviewed medical records of UPJO patients treated with LP using the Anderson-Hynes dismembered technique. After the approval of the Ethics Committee of Kahramanmaraş Sütcü İmam University (approval number: 02.12.2020-19), data between February 2016 and March 2020 were collected from our institution. Among the patients who underwent pyeloplasty ( $\mathrm{n}=27)$ in this period of time, those who had open surgery $(n=4)$ were excluded and the remaining 23 patients were included in the study.

Based on clinical symptoms such as flank pain, chronic urinary tract infection (UTI), and urolithiasis, the diagnosis of UPJO was confirmed by radiological studies such as ultrasound (US), intravenous urography (IVU), and diuretic renogram (Tc-99m mercaptoacetyltriglycine [MAG3] or diethylenetriaminepentaacetic acid [DTPA]). Surgical indications were determined according to being symptomatic UPJO and presence of obstruction on pre-operative radiological examinations (progressive hydronephrosis on US, delayed nephrogram, and/or drainage with hydronephrosis on IVU and impaired renal function and/or obstructive curve with delayed 50\% drainage after $20 \mathrm{~min}$ on diuretic renal scan).

\section{Surgical Technique}

LP by the transperitoneal route with the dismembered technique was applied in all patients. After the patient was placed in the lateral decubitus position, an $11 \mathrm{~mm}$ optic trocar was used to enter the abdomen and pneumoperitoneum was created. A standard 3-port technique was used, but the $4^{\text {th }}$ port could be used when necessary or for liver retraction on the right side. If the patient was not obese in whom the port locations were displaced laterally and cranially, the camera port was inserted above the umbilicus. $10 \mathrm{~mm}$ and $5 \mathrm{~mm}$ trocars were inserted 2-3 $\mathrm{cm}$ below the costal margin in the mid-clavicular line and at the midpoint between the umbilicus and the anterior superior iliac spine, respectively.

The colon was mobilized along the told line until the medial aspect of the lower pole of the kidney and the proximal ureter was visualized. The ureteropelvic junction (UPJ) was exposed by dissecting to the pelvis and proximal ureter, and the atretic or obstructed UPJ segment was excised. After lateral ureter spatulation and pelvis reduction, if necessary, the posterior wall was sutured with running 4-0 polyglycolic acid sutures. Later, a ureteral indwelling double-J (DJ) stent was passed an antegrade fashion and anastomosis was completed. Finally, a 10Fr drain was left through one of the lateral ports. The Satava and Clavien-Dindo classification systems were used for grading of operative and post-operative complications, respectively. ${ }^{[11,12]}$ The time between the first skin incision and the last skin suture was determined as the operation time.

\section{Follow-up}

The urethral catheter was pulled out on the 1st day of the operation. The drain catheter was pulled out when the drain amount was $<50 \mathrm{ml}$ before discharged. The ureteral DJ stent was removed after 6 weeks postoperatively. In the follow-up, urinary US and/or IVU was performed in the post-operative 3rd month, and MAG3 or DTPA renal scan at the 6th month, and annually thereafter. The surgical success was defined as absence or improvement of symptoms and resolution of hydronephrosis in US/IVU and/or drainage on diuretic renal scan.

\section{Study Outcomes}

The charts of patients such as demographic data, presenting complaint, pre-operative imaging, operation time, presence of crossing aberrant vessel, post-operative complications, hemoglobin drop, length of drain and hospital stay, and success rates were evaluated. 


\section{Statistical Analysis}

Continuous variables were presented as mean \pm SD (minmax) and categorical data as numbers and percentages. For statistical analysis, SPSS program (version 22.0, IBM, USA) was used.

\section{Results}

Of the 23 patients, 22 had primary and one patient had secondary UPJO previously treated with retrograde endopyelotomy. All demographic data and clinical features are summarized in Table 1. With a male predominance of 56.5\%, the mean patient age was $25.5 \pm 17.1$ (4-63) years. Twenty (87\%) patients were clinically symptomatic with mainly flank pain, and only 3 (13\%) patients were detected incidentally. Four (17.4\%) of the patients had concomitant kidney stones. Decompression of the pelvicalyceal system was

Table 1. Basic demographic data and clinical features

\begin{tabular}{|c|c|}
\hline \multicolumn{2}{|l|}{ Laparoscopic pyeloplasty } \\
\hline Patients, $\mathrm{n}$ & 23 \\
\hline Age, years* & $25.5 \pm 17.1(4-63)$ \\
\hline \multicolumn{2}{|l|}{ Gender, n (\%) } \\
\hline Male & $13(56.5)$ \\
\hline Female & $10(43.5)$ \\
\hline \multicolumn{2}{|l|}{ Side, n (\%) } \\
\hline Right & $10(43.5)$ \\
\hline Left & $13(56.5)$ \\
\hline \multicolumn{2}{|l|}{ Clinical symptoms, n (\%) } \\
\hline Flank pain & $13(56.5)$ \\
\hline $\begin{array}{l}\text { Flank pain + urinary } \\
\text { tract infection }\end{array}$ & $3(13.0)$ \\
\hline Flank pain + kidney stone & $4(17.4)$ \\
\hline Incidental & $3(13.0)$ \\
\hline \multicolumn{2}{|l|}{ Hydronephrosis, n (\%) } \\
\hline Grades 1-2 & $5(21.7)$ \\
\hline Grades 3-4 & $18(78.3)$ \\
\hline \multicolumn{2}{|l|}{$\begin{array}{l}\text { Impaired renal function } \\
\text { (at renal scan), } \mathrm{n}(\%)\end{array}$} \\
\hline Below 40 & $12(52.2)$ \\
\hline Above 40 & $11(47.8)$ \\
\hline \multicolumn{2}{|l|}{ Causes of obstruction, n (\%) } \\
\hline Aberrant crossing vessel & $13(56.5)$ \\
\hline Adynamic/stenotic segment & $9(39.1)$ \\
\hline High insertion & $1(4.3)$ \\
\hline Preoperative creatinine, $\mathrm{mg} / \mathrm{dL}$ * & $0.7 \pm 0.3(0.3-1.2)$ \\
\hline
\end{tabular}

needed in two patients due to infection, DJ stent was used in one, percutaneous nephrostomy was used in the other. Of the patients, 18 had severe hydronephrosis (Grades 3-4) and $52.2 \%$ had renal function below $40 \%$. All patients had impaired drainage in the diuretic renogram.

Table 2 contains all operative and post-operative outcomes. The mean operative time was $214.8 \pm 43.1$ (160-310) min, while no blood transfusion was given to any of the patients. Means of drain stay time and hospital stay time were $2.8 \pm 1.0$ (2-7) and 3.5 \pm 1.8 (2-9) days, respectively. Although no major operative or post-operative complications were seen in our series, 2 (8.7\%) patients had minor operative complications and 4 (17.3\%) patients had minor postoperative complications. One of the operative complications was local subcutaneous emphysema, while the other was hypercapnia leading to open surgery. Clavien Grade 1 complications were infection and ischemic hepatitis, Grade 2 complication was sub-ileus due to prolonged drainage corrected by keeping the Foley catheter for 7 days. The mean follow-up period of all patients followed for at least 3 months was $13.9 \pm 7.8(3-34)$ and the surgical success rate was $95.7 \%$. After removal of the DJ stent, one patient with flank pain and poor drainage in the renal scan was treated with retrograde balloon dilatation.

\section{Table 2. Operative and post-operative outcomes}

\begin{tabular}{lc} 
Laparoscopic pyeloplasty & Mean \pm SD (range) \\
\hline Operative time, min & $214.8 \pm 43.1(160-310)$ \\
Hemoglobin drop, g/dL & $0.9 \pm 0.5(0.2-2.0)$ \\
Drain stay time, days & $2.8 \pm 1.0(2-7)$ \\
Hospital stay, days & $3.5 \pm 1.8(2-9)$ \\
Follow-up, months & $13.9 \pm 7.8(3-34)$ \\
Success, $\mathrm{n}$ (\%) & $22(95.7)$ \\
Intraoperative & $2(8.7)$ \\
complications*, $\mathrm{n}(\%)$ & $1(4.3)$ \\
$\quad \begin{array}{l}\text { Subcutaneous } \\
\text { emphysema (grade 1) }\end{array}$ & $1(4.3)$ \\
$\quad$ Hypercapnia (grade 1) & $4(17.3)$ \\
$\begin{array}{l}\text { Post-operative } \\
\text { complications**, } \mathrm{n} \text { (\%) }\end{array}$ & $2(8.7)$ \\
$\quad \begin{array}{l}\text { Urinary tract infection (Grade 1) } \\
\text { Ischemic hepatitis (Grade 1) }\end{array}$ & $1(4.3)$ \\
$\quad \begin{array}{l}\text { Sub-ileus associated } \\
\text { with urine leakage (Grade 2) }\end{array}$ & $1(4.3)$
\end{tabular}

*Graded according to Satava classification system.**Graded according to Clavien-Dindo classification system. 


\section{Discussion}

After the first reconstructive procedure for UPJO was performed by Trendelenburg in 1886, with efforts to improve the surgical technique, OP with the dismembered technique was defined by Anderson and Hynes in 1949. ${ }^{[13]}$ However, the significant incisional morbidity of open surgery, such as increased analgesic requirement and long recovery periods, has led to the search for minimally invasive surgery. With the advent of endourology, endoscopic surgeries such as antegrade or retrograde endopyelotomy and balloon dilatation have been performed, but have little place in treatment due to varying success rates and high recurrence rates. ${ }^{[6,7]}$ After Schuessler et al. described LP in 1993, ${ }^{[8]}$ LP was the first minimally invasive technique that achieved success rates of OP worldwide. ${ }^{[9]}$ Recently, robot-assisted pyeloplasty, which has been used with advances in robotic surgery in the past decade, had similar success and complication rates with $\mathrm{LP},{ }^{[14]}$ but is not available in every center due to its high cost. Therefore, LP is still preferred as the standard treatment in many centers as its low morbidity, short hospital stay, and short recovery time.

Most patients present with symptoms of back pain or recurrent UTI in UPJO. ${ }^{[15,16]}$ It may also be incidentally found, as a result of the widespread use of imaging methods. ${ }^{[4]}$ In the series of Demirdağ et al., ${ }^{[16]} 50 \%$ of the patients had pain, $18.1 \%$ had UTI, 5.2\% had hematuria, and $26.7 \%$ were asymptomatic. A review of historical surgical and angiographic and endoechographic series showed $47 \%$ and $40 \%$ accompanying crossing vessel in cases of surgical hydronephrosis, respectively. ${ }^{[17]}$ The incidence of kidney stone has been reported to be approximately $16-30 \% .{ }^{[14,18-}$ ${ }^{20]}$ In the present study, while flank pain was the primary symptom with $56.5 \%, 13 \%$ of the patients with UPJO were found incidentally. Of the 23 patients, 13 (56.5\%) presented with crossing aberrant vessel and $4(17.4 \%)$ with kidney stone. As can be seen, although our sample size is small, the clinical features of our cases are consistent with the studies in the literature.

While the transperitoneal approach is more widely used as it provides a wider operating area for working within which to suture and familiar and identifiable anatomical landmarks, the retroperitoneal approach may be preferred for patients with previous abdominal surgery or morbidly obese patients. ${ }^{[2]}$ In both the transperitoneal and retroperitoneal approaches, data consistently show low perioperative morbidity and high success rates (94.1$100 \%$ ) in series including $>100$ patients. ${ }^{[21]}$ We preferred the transperitoneal route for this initial series. Moreover, our repair technique was the Anderson-Hynes dismembered technique for all patients. We achieved a rate similar to the surgical success rate of large series with $95.7 \%$.
Global acceptance of LP has a steep learning curve due to difficult intracorporeal suturing. ${ }^{[22]}$ However, operation time has been decreased as the number of cases of the surgeon and worldwide experience in laparoscopic surgery increases. Bansal et al. ${ }^{[23]}$ presented the mean operative time as $244.21 \pm 41.73$ in their LP series consisting of 28 patients. On the other hand, in a recent study with $27 \mathrm{LP}$ cases, the operative time was $180 \pm 72 .{ }^{[24]}$ Although it was our first LP series, the mean operation time was $214 \pm 43.1$.

In LP series involving a large number of patients, complication rates range between $12.9 \%$ and $15.8 \%$, while this rate increases to $22.5 \%$ in studies with a small number of cases. ${ }^{[25-27]}$ In the present study, there were two intraoperative Satava Grade 1 complications such as local subcutaneous emphysema and hypercapnia. There were three postoperative Clavien Grade 1 complications, two of which were UTIs, and one was ischemic hepatitis. Sub-ileus associated with urinary leakage in one patient was evaluated as a Clavien Grade 2 complication. Consequently, the post-operative complication rate was $17.3 \%$, and no major complications were observed.

Since LP does not have a large incision like OP, recovery times are shorter. In the review of large series $(>100$ patients) of transperitoneal LP, length of hospital stay ranged from 2.7 to 5.1 days. ${ }^{[2]}$ Furthermore, in a recent comparative study, the mean hospital stay was significantly shorter for LP than for OP $(2.7 \pm 1.8$ days and $9.09 \pm 7.3$ days, respectively). ${ }^{[28]}$ In our study, the mean hospital stay was $3.5 \pm 1.8$ (2-9) days, consistent with the literature.

The limitations of our study are retrospective nature and the small sample size which does not allow sufficient generalization. However, since this study includes our first surgical experiences, it will contribute to some centers starting to perform LP.

\section{Conclusion}

Due to increased worldwide experience in laparoscopic surgery, the challenge on intracorporeal suturing of LP in initial cases is overcome in a short time. With a high success rate, low post-operative complication rate, and low hospital stay, our initial series results are consistent with high-volume studies in the literature. LP will be used as a standard treatment in many centers for a long time unless the high cost of robotic surgery decreases.

\section{Disclosures}

Ethichs Committee Approval: The study was approved by the Kahramanmaras Sutçu Imam University Local Ethics Committee with approval number 02.12.2020-19. 
Peer-review: Externally peer-reviewed.

Conflict of Interest: None declared.

Authorship Contributions: Concept - M.K.D.; Design O.B.; Supervision - T.Ş.; Materials - Ö.F.B.; Data collection and/or processing - O.B.; Analysis and/ or interpretation - Ö.F.B., S.R.; Literature search - M.K.D.; Writing - M.K.D.; Critical review - T.Ş., S.R.

\section{References}

1. Hanske J, Sanchez A, Schmid M, Meyer CP, Abdollah F, Roghmann $\mathrm{F}$, et al. Comparison of 30-day perioperative outcomes in adults undergoing open versus minimally invasive pyeloplasty for ureteropelvic junction obstruction: Analysis of 593 patients in a prospective national database. World $\mathrm{J}$ Urol 2015;33:2107-13. [CrossRef]

2. Khan F, Ahmed K, Lee N, Challacombe B, Khan MS, Dasgupta $P$. Management of ureteropelvic junction obstruction in adults. Nat Rev Urol 2014;11:629-38. [CrossRef]

3. Chevalier RL, Thornhill BA, Forbes MS, Kiley SC. Mechanisms of renal injury and progression of renal disease in congenital obstructive nephropathy. Pediatr Nephrol (Berlin, Germany) 2010;25:687-97. [CrossRef]

4. Park JM, Bloom DA. The pathophysiology of UPJ obstruction. Current concepts. Urol Clin North Am 1998;25:161-9.

5. Anderson JC, Hynes W. Retrocaval ureter: A case diagnosed pre-operatively and treated successfully by a plastic operation. Br J Urol 1949;21:209-14. [CrossRef]

6. Stein RJ, Gill IS, Desai MM. Comparison of surgical approaches to ureteropelvic junction obstruction: Endopyeloplasty versus endopyelotomy versus laparoscopic pyeloplasty. Curr Urol Rep 2007;8:140-9. [CrossRef]

7. Motola JA, Badlani GH, Smith AD. Results of 212 consecutive endopyelotomies: An 8-'year followup. J Urol 1993;149:453-6.

8. Schuessler WW, Grune MT, Tecuanhuey LV, Preminger GM. Laparoscopic dismembered pyeloplasty. J Urol 1993;150:1795-9. [CrossRef]

9. Adeyoju AB, Hrouda D, Gill IS. Laparoscopic pyeloplasty: The first decade. BJU Int 2004;94:264-7. [CrossRef]

10. Baldwin DD, Dunbar JA, Wells N, McDougall EM. Single-center comparison of laparoscopic pyeloplasty, Acucise endopyelotomy, and open pyeloplasty. J Endourol 2003;17:155-60.

11. Rassweiler JJ, Teber D, Frede T. Complications of laparoscopic pyeloplasty. World J Urol 2008;26:539-47. [CrossRef]

12. Dindo $D$, Demartines $N$, Clavien PA. Classification of surgical complications: A new proposal with evaluation in a cohort of 6336 patients and results of a survey. Ann Surg 2004;240:205-13. [CrossRef]

13. Poulakis V, Witzsch U, Schultheiss D, Rathert P, Becht E. [History of ureteropelvic junction obstruction repair (pyeloplasty). From Trendelenburg (1886) to the present]. Urol A 2004;43:1544-59. [CrossRef]

14. Braga LH, Pace K, DeMaria J, Lorenzo AJ. Systematic review and meta-analysis of robotic-assisted versus conventional laparoscopic pyeloplasty for patients with ureteropelvic junction obstruction: Effect on operative time, length of hospital stay, postoperative complications, and success rate. Eur Urol 2009;56:848-57. [CrossRef]

15. Tolstrup RS, Pank MT, Sander L, Dørflinger T. Laparoscopic pyeloplasty for ureteropelvic junctions obstruction in adults: 6 years' experience in one center. Biomed Res İnt 2017;2017:6743512. [CrossRef]

16. Demirdağ çÖ, Çitgez S, Önal B, Talat Z. Outcomes of laparoscopic transperitoneal pyeloplasty for the treatment of ureteropelvic junction obstruction in adult patients. J Urol Surg 2018;5:174-9. [CrossRef]

17. Van Cangh PJ, Nesa S, Galeon M, Tombal B, Wese FX, Dardenne $A N$, et al. Vessels around the ureteropelvic junction: Significance and ımaging by conventional radiology. J Endourol 1996;10:111-9. [CrossRef]

18. Nayyar R, Gupta NP, Hemal AK. Robotic management of complicated ureteropelvic junction obstruction. World J Urol 2010;28:599-602. [CrossRef]

19. Skolarikos A, Dellis A, Knoll T. Ureteropelvic obstruction and renal stones: Etiology and treatment. Urolithiasis 2015;43:5-12.

20. Stasinou T, Bourdoumis A, Masood J. Forming a stone in pelviureteric junction obstruction: Cause or effect? Int Braz J Urol 2017;43:13-9. [CrossRef]

21. Autorino R, Eden C, El-Ghoneimi A, Guazzoni G, Buffi N, Peters $\mathrm{CA}$, et al. Robot-assisted and laparoscopic repair of ureteropelvic junction obstruction: A systematic review and metaanalysis. Eur Urol 2014;65:430-52. [CrossRef]

22. Türk IA, Davis JW, Winkelmann B, Deger S, Richter F, Fabrizio $M D$, et al. Laparoscopic dismembered pyeloplasty--the method of choice in the presence of an enlarged renal pelvis and crossing vessels. Eur Urol 2002;42:268-75. [CrossRef]

23. Bansal P, Gupta A, Mongha R, Narayan S, Das RK, Bera M, et al. Laparoscopic versus open pyeloplasty: Comparison of two surgical approaches a single centre experience of three years. Indian J Surg 2011;73:264-7. [CrossRef]

24. Griessner $H$, Oberhammer $L$, Pallauf $M$, Oswald $D$, Kunit $T$, Colleselli D, et al. [A retrospective comparison of robotic assisted and conventional laparoscopic pyeloplasty in two centres]. Urol A 2020;2020:01414-3.

25. Shoma AM, El Nahas AR, Bazeed MA. Laparoscopic pyeloplasty: A prospective randomized comparison between the transperitoneal approach and retroperitoneoscopy. J Urol 2007;178:2020-4; discussion 4. [CrossRef]

26. Moon DA, El-Shazly MA, Chang CM, Gianduzzo TR, Eden CG. Laparoscopic pyeloplasty: Evolution of a new gold standard. Urology 2006;67:932-6. [CrossRef]

27. Inagaki T, Rha KH, Ong AM, Kavoussi LR, Jarrett TW. Laparoscopic pyeloplasty: Current status. BJU Int 2005;95 Suppl 2:102-5. [CrossRef]

28. Gadelmoula $M$, Abdel-Kader $M S$, Shalaby $M$, Abdelrazek $M$, Moeen AM, Zarzour MA, et al. Laparoscopic versus open pyeloplasty: A multi-institutional prospective study. Cent Eur J Urol 2018;71:342-5. 